\title{
Resistance to Benomyl and Thiophanate-methyl in Didymella bryoniae from South Carolina and New York
}

\author{
Anthony P. Keinath, Department of Plant Pathology and Physiology, Clemson University, Coastal Research and \\ Education Center, Charleston, SC 29414-5332; and Thomas A. Zitter, Department of Plant Pathology, Cornell \\ University, Ithaca, NY 14853-5908
}

\begin{abstract}
Keinath, A. P., and Zitter, T. A. 1998. Resistance to benomyl and thiophanate-methyl in Didymella bryoniae from South Carolina and New York. Plant Dis. 82:479-484.

An initial collection of 7 isolates of Didymella bryoniae were grown on media amended with 0 , $1,3.2,10,31.2$, or $100 \mathrm{mg}$ benomyl per liter. Four isolates grew at all five concentrations of benomyl, but the other 3 isolates did not grow at concentrations $>1 \mathrm{mg} /$ liter. Colony diameter of the four resistant isolates was reduced by $50 \%$ at $33.1 \mathrm{mg}$ benomyl per liter, relative to growth on nonamended medium. Of 394 isolates tested, 182 isolates were resistant to benomyl; 178 of these resistant isolates were from South Carolina, 1 was from New York, and 3 were from Florida. Of 196 isolates grown on medium amended with $100 \mathrm{mg} /$ liter thiophanate-methyl, 95 were sensitive and 101 were resistant. Essentially all isolates that were resistant to benomyl were resistant to thiophanate-methyl. In greenhouse tests, watermelon plants were sprayed with $0,1.5,15,150$, or $1,500 \mathrm{mg}$ benomyl per liter and inoculated 1 day later with either a sensitive or a resistant isolate of $D$. bryoniae. Relative percent leaf area diseased was greater $(P \leq 0.02)$ for the resistant isolate than for the sensitive isolate at $\geq 1.5 \mathrm{mg}$ benomyl per liter. The occurrence of pathogenic, benzimidazole-resistant $D$. bryoniae in the eastern United States may reduce the effectiveness of benzimidazole fungicides for gummy stem blight management.
\end{abstract}

Additional keywords: black rot, cucurbits, fungicide resistance

The benzimidazole fungicides benomyl and thiophanate-methyl have been used widely to control Ascomycete fungal plant pathogens. These fungicides move systemically in the xylem of the host plant, which allows control of established infections and protection of host tissue that develops after fungicide application $(4,25)$. Benomyl binds to beta-tubulin, thereby preventing the formation of microtubules, which leads to the disruption of chromosome migration during mitosis and meiosis (2). Resistance to benomyl and thiophanate-methyl has developed in a number of foliar fungal plant pathogens (22), including Botrytis cinerea $(8,29)$, Venturia inaequalis $(10,16)$, Pseudocercosporella herpotrichoides (21), and the powdery mildews Sphaerotheca fuliginea (19) and Uncinula necator $(23,30)$.

Resistance to benomyl in Didymella bryoniae (Auersw.) Rehm, the causal agent

Corresponding author: A. P. Keinath

E-mail: tknth@clemson.edu

Technical contribution No. 4313 of the South Carolina Agriculture and Forestry Research System. These studies were funded in part by Hatch Projects NY417 and SC01628 and by the NYS IPM program.

Accepted for publication 3 January 1998.

Publication no. D-1998-0310-01R

(C) 1998 The American Phytopathological Society of gummy stem blight and black rot on cucurbits, was first detected in Greece in 1981 (18). Resistant isolates accounted for $74.5 \%$ of the isolates recovered from cucumbers treated with benomyl in 15 of 20 greenhouses sampled. In the Netherlands in 5 of 23 greenhouses, $17 \%$ of the isolates were resistant to benomyl (29). In both countries, benomyl-resistant isolates were as virulent as sensitive isolates on inoculated cucumber plants. D. bryoniae isolates resistant to benomyl also were reported from Japan (11).

Benomyl and, to a lesser extent, thiophanate-methyl have been used on cucurbits to control not only gummy stem blight $(9,12,28)$ but also powdery mildew (19) and anthracnose $(5,17)$. In a recent study on watermelon, a combination of chlorothalonil plus benomyl was only slightly more effective for control of gummy stem blight than application of chlorothalonil alone (12). The development of resistance to systemic benzimidazole fungicides in $D$. bryoniae would make control of gummy stem blight and black rot more difficult, since $D$. bryoniae can infect cucurbit leaves after only $1 \mathrm{~h}$ of leaf wetness, (27) and systemic activity is often critical for successful control.

The objective of this study was to determine the sensitivity to benomyl and thiophanate-methyl of field-collected isolates of $D$. bryoniae from South Carolina and New York. The level of resistance and the ability of a resistant isolate to incite gummy stem blight on plants treated with benomyl also were determined. Preliminary results have been presented $(14,15)$.

\section{MATERIALS AND METHODS}

Isolate collection. Leaves, stems, or fruit with symptoms of gummy stem blight or black rot were collected from cucurbits grown in commercial fields, greenhouses, or experimental plots (31) in South Carolina and New York from 1992 to 1996 (Table 1). In 1995 and 1996, commercial fields in the three primary cucurbit-production areas of South Carolina and in Upstate New York were sampled more intensively to collect 10 to 20 isolates per field. Two fields each of watermelon and cantaloupe were sampled in the Savannah River Valley (Colleton and Barnwell counties) and one field of each crop was sampled on Edisto Island (Charleston County) and near the North Carolina-South Carolina border (Chesterfield County). Likewise, one pumpkin field and four cantaloupe fields were sampled in five New York counties. In each of these 13 fields in South Carolina and New York, 1 or 2 leaves or stem sections with pycnidia of $D$. bryoniae were collected from at least 25 plants along a diagonal transect through the field. Leaves or stem sections from individual plants were placed in separate polyethylene bags and transported to the laboratory in a cooler. Tissue pieces were surface disinfested in $0.5 \%$ sodium hypochlorite for 30 to $60 \mathrm{~s}$ and placed on onequarter-strength potato dextrose agar (QPDA) plates held at ambient temperature $\left(22\right.$ to $\left.25^{\circ} \mathrm{C}\right)$ under a 12 -h photoperiod. Colonies of $D$. bryoniae growing from the pieces were transferred to fresh QPDA, and single-spore subcultures were obtained and stored on QPDA at $4{ }^{\circ} \mathrm{C}$. A total of 394 isolates were tested for fungicide resistance, including 16 isolates of $D$. bryoniae collected between 1989 and 1992 (13).

Fungicide resistance tests. A subset of isolates was used to construct a dose-response curve to benomyl. Seven isolates of D. bryoniae (C06, SSQ1, W03, W04, W6B, W26, and NY1) were selected to represent different locations (Florida, New York, and South Carolina), hosts (watermelon, cantaloupe, and summer squash), plant parts affected (leaf, fruit, and seed), and year of original isolation (1989 to 1992 ; 13). Aliquots of a stock 
solution of technical-grade benomyl dissolved in acetone were added to molten QPDA to achieve final concentrations of 1, $3.2,10,31.2$, or $100 \mathrm{mg}$ benomyl per liter medium. These concentrations were chosen because they are equally spaced on a $\log _{10}$ scale (20). Additional acetone was added to media that received $<100 \mathrm{mg}$ benomyl per liter, so that each medium contained the same concentration of acetone, $10.3 \mathrm{ml} /$ liter or $1.0 \%$ by volume. QPDA plates with and without acetone were used as controls. Isolates were grown on QPDA at $21^{\circ} \mathrm{C}$ in the dark for 3 days to produce actively growing source cultures. Plugs $0.6 \mathrm{~cm}$ in diameter were cut from the source cultures and inverted onto three replicate plates with $20 \mathrm{ml}$ control or benomyl-amended medium per plate. After 6 days of growth at $21^{\circ} \mathrm{C}$ in the dark, two perpendicular colony diameters were measured on the bottom of each plate. The diameter of the agar plug was subtracted from each measurement. The two colony diameters were averaged for each plate and a mean diameter was calculated from the three replicate plates. Relative colony diameter was calculated as (diameter on benomyl-amended medium)/(diameter on control medium with acetone) (20). The experiment was done twice.

A quadratic equation was fit to the dose response curve of the four resistant isolates. From this equation, the $50 \%$ effective concentration $\left(\mathrm{EC}_{50}\right)$ was calculated to be $33.1 \mathrm{mg}$ benomyl per liter. This concentration of benomyl, and the corresponding concentration of acetone alone (3.1 ml/liter) for control plates, was used to test all other $D$. bryoniae isolates for resistance to benomyl. All isolates were tested twice, with three and two replicate plates in the first and second tests, respectively. Isolates known to be sensitive (W3) or resistant (NY1) to benomyl were included in all tests as controls. Mean relative colony diameters were compared with the expected value of 0.5 using $t$ tests, $P \leq$ 0.05 . Isolates that had relative colony diameters significantly greater than 0.5 at $33.1 \mathrm{mg}$ benomyl per liter were grown on QPDA plus $50 \mathrm{mg}$ benomyl per liter. Five of these isolates (B19, C107, D17, J21, and $\mathrm{K} 12$, collected from watermelon or cantaloupe in South Carolina in 1995 or 1996) and NY1 were grown on QPDA amended with $1,3.2,10,31.2$, or $100 \mathrm{mg}$ benomyl per liter, as described above, to determine if their response to benomyl differed from that of resistant isolate NY1 over a range of concentrations. All experiments were done twice.

Eight isolates were used initially to determine the sensitivity of $D$. bryoniae to a second benzimidazole fungicide, thiophanate-methyl. Isolates C06, W03, W04, W6B, W26, NY1, F18, and K12 were selected to represent different locations (Florida, New York, and South Carolina), hosts (watermelon and cantaloupe), plant parts affected (leaf, fruit, and seed), year of original isolation (1989 to 1995), and response to benomyl (sensitive, resistant, and highly resistant). QPDA was amended with $0,1,3.2,10,31.2$, or $100 \mathrm{mg} / \mathrm{liter}$ technical-grade thiophanate-methyl dissolved in acetone plus additional acetone to equalize the acetone concentration ( $10.3 \mathrm{ml} /$ liter $)$.

Table 1. Sensitivity of isolates of Didymella bryoniae collected in the years 1992 to 1996 from South Carolina and New York to benomyl and thiophanatemethyl, based on colony diameter on fungicide-amended medium relative to growth on nonamended medium

\begin{tabular}{|c|c|c|c|c|c|c|}
\hline \multirow[b]{2}{*}{ Date collected } & \multirow[b]{2}{*}{ Host } & \multirow[b]{2}{*}{ Plant part } & \multirow{2}{*}{$\begin{array}{c}\text { Location } \\
\text { (County, state) }\end{array}$} & \multirow{2}{*}{$\begin{array}{c}\text { Benomyl } \\
\text { R/N }\end{array}$} & \multicolumn{2}{|c|}{ Thiophanate-methyl } \\
\hline & & & & & $\mathbf{M S} / \mathbf{N}^{\mathbf{b}}$ & $\mathbf{R} / \mathbf{N}^{\mathrm{c}}$ \\
\hline 1992 & Pumpkin & Leaf & Charleston, SC & $4 / 5$ & $1 / 5$ & $4 / 5$ \\
\hline 1993 & Cantaloupe & Leaf & Bamberg, SC & $2 / 2$ & $\mathrm{nt}^{\mathrm{d}}$ & nt \\
\hline 1993 & Cantaloupe & Leaf & Chesterfield, SC & $0 / 2$ & $\mathrm{nt}$ & $\mathrm{nt}$ \\
\hline 1993 & Cantaloupe & Seedling & Colleton, SC & $4 / 4$ & $1 / 4$ & $3 / 4$ \\
\hline 1993 & Cantaloupe & Leaf & Colleton, SC & $3 / 5$ & $0 / 5$ & $5 / 5$ \\
\hline 1993 & Cantaloupe & Stem/Leaf & Colleton, SC & $1 / 2$ & nt & $\mathrm{nt}$ \\
\hline 1993 & Honeydew & Leaf & Allendale, SC & $3 / 4$ & $1 / 4$ & $3 / 4$ \\
\hline 1993 & Watermelon & Leaf & Allendale, SC & $5 / 6$ & $0 / 6$ & $5 / 6$ \\
\hline 1993 & Watermelon & Leaf & Bamberg, SC & $3 / 3$ & $0 / 3$ & $3 / 3$ \\
\hline 1993 & Watermelon & Leaf & Hampton, SC & $1 / 5$ & $4 / 5$ & $1 / 5$ \\
\hline 1993 & Pumpkin & Leaf & Charleston, SC & $1 / 2$ & nt & $\mathrm{nt}$ \\
\hline 1994 & Butternut squash & Leaf & Tompkins, NY & $0 / 37$ & $\mathrm{nt}$ & $\mathrm{nt}$ \\
\hline 1994 & Cantaloupe & Leaf & Charleston, SC & $7 / 8$ & $\mathrm{nt}$ & $\mathrm{nt}$ \\
\hline 1994 & Cantaloupe & Fruit & Charleston, SC & $5 / 5$ & $\mathrm{nt}$ & $\mathrm{nt}$ \\
\hline 1994 & Cucumber & Leaf & Charleston, SC & 7/9 & $\mathrm{nt}$ & $\mathrm{nt}$ \\
\hline 1994 & Watermelon & Leaf & Charleston, SC & $2 / 4$ & $\mathrm{nt}$ & $\mathrm{nt}$ \\
\hline 1994 & Watermelon & Seedling & Charleston, SC & $0 / 4$ & $4 / 4$ & $0 / 4$ \\
\hline 1994 & Watermelon & Seedling & Charleston, SC & $0 / 3$ & $0 / 3$ & $0 / 3$ \\
\hline 1994 & Watermelon & Leaf & Charleston, SC & $5 / 5$ & $0 / 5$ & $5 / 5$ \\
\hline 1994 & Watermelon & Leaf & Colleton, SC & $5 / 5$ & $0 / 5$ & $5 / 5$ \\
\hline 1995 & Pumpkin & Leaf & Ontario, $\mathrm{NY}$ & $0 / 60$ & $\mathrm{nt}$ & $\mathrm{nt}$ \\
\hline 1995 & Cantaloupe & Leaf & Barnwell, SC & $5 / 12$ & $1 / 10$ & $4 / 10$ \\
\hline 1995 & Cantaloupe & Leaf & Charleston, SC & $19 / 19$ & $0 / 10$ & $10 / 10$ \\
\hline 1995 & Cantaloupe & Leaf & Chesterfield, SC & $9 / 20$ & $3 / 10$ & $0 / 10$ \\
\hline 1995 & Cantaloupe & Leaf & Colleton, SC & $18 / 20$ & $0 / 10$ & $9 / 10$ \\
\hline 1995 & Watermelon & Seedling & Horry, SC & $0 / 6$ & $6 / 6$ & $0 / 6$ \\
\hline 1995 & Watermelon & Leaf & Charleston, SC & $20 / 20$ & $0 / 10$ & $10 / 10$ \\
\hline 1995 & Watermelon & Leaf & Chesterfield, SC & $15 / 20$ & $2 / 10$ & $6 / 10$ \\
\hline 1995 & Watermelon & Leaf & Colleton, SC & $11 / 11$ & $0 / 8$ & $8 / 8$ \\
\hline 1995 & Watermelon & Leaf & Colleton, SC & $14 / 14$ & $0 / 10$ & $10 / 10$ \\
\hline 1996 & Cantaloupe & Leaf & Columbia, NY & $0 / 10$ & $7 / 10$ & $0 / 10$ \\
\hline 1996 & Cantaloupe & Leaf & Niagara, NY & $0 / 10$ & $10 / 10$ & $0 / 10$ \\
\hline 1996 & Cantaloupe & Leaf & Schoharie, NY & $0 / 10$ & $2 / 10$ & $0 / 10$ \\
\hline 1996 & Cantaloupe & Leaf & Washington, NY & $0 / 10$ & $8 / 10$ & $0 / 10$ \\
\hline 1996 & Cantaloupe & Seedling & Barnwell, SC & $0 / 5$ & $2 / 5$ & $0 / 5$ \\
\hline 1996 & Cantaloupe & Seedling & Barnwell, SC & $6 / 6$ & $0 / 5$ & $5 / 5$ \\
\hline 1996 & Cantaloupe & Seedling & Barnwell, SC & $0 / 5$ & $0 / 5$ & $0 / 5$ \\
\hline
\end{tabular}

${ }^{\mathrm{a}} \mathrm{R}=$ number of isolates resistant to benomyl, (i.e., relative colony diameter $>0.10$ at $33.1 \mathrm{mg} /$ liter). $\mathrm{N}=$ number of isolates tested.

${ }^{\mathrm{b}} \mathrm{MS}=$ number of isolates moderately sensitive to thiophanate-methyl, (i.e., relative colony diameter $<0.20$ at $100 \mathrm{mg} / \mathrm{liter}$ ). $\mathrm{N}=$ number of isolates tested.

${ }^{\mathrm{c}}$ Number of isolates resistant to thiophanate-methyl, (i.e., relative colony diameter $\geq 0.20$ at $100 \mathrm{mg} / \mathrm{liter}$ ). $\mathrm{N}=$ number of isolates tested.

${ }^{\mathrm{d}}$ Not tested. 
Cultures were grown as described above and relative colony diameters were calculated. A concentration of $100 \mathrm{mg} / \mathrm{liter}$ thiophanate-methyl was selected to test 78 isolates of D. bryoniae collected in South Carolina in 1995, 70 additional isolates from South Carolina, and 40 isolates collected in New York in 1996. Isolates that were moderately sensitive (W03) and resistant (NY1) to thiophanate-methyl were included in all experiments as controls.

Disease severity comparisons. Watermelon (Citrullus lanatus (Thunb.) Matsum. \& Nakai 'Jubilee II') seedlings were grown as described previously (13). When the first true leaf was fully expanded, 8 to 10 days after seeding, plants were sprayed to runoff with suspensions of $1.5,15,150$, or $1,500 \mathrm{mg}$ benomyl per liter (Benlate 50WP); control plants were sprayed with sterile distilled water. One day later, plants were inoculated with isolate W03 (sensitive to benomyl) or NY1 (resistant to benomyl) and incubated as described previously (13). A completely randomized factorial design was used, with four replicate pots each containing three plants for each treatment combination of benomyl concentration and isolate. The experiment was conducted three times. Percent leaf surface area with disease symptoms was estimated on individual plants with the Horsfall-Barratt scale 4 days after inoculation (7). Diseased leaf tissue from one plant per replicate was cultured, as described previously, to reisolate the pathogen. Horsfall-Barratt ratings were converted to percent disease severity with the midpoint of the percent ranges represented by the Horsfall-Barratt values. A relative disease severity for each isolate was calculated for each concentration of benomyl as (disease severity on benomyltreated plants)/(disease severity on control

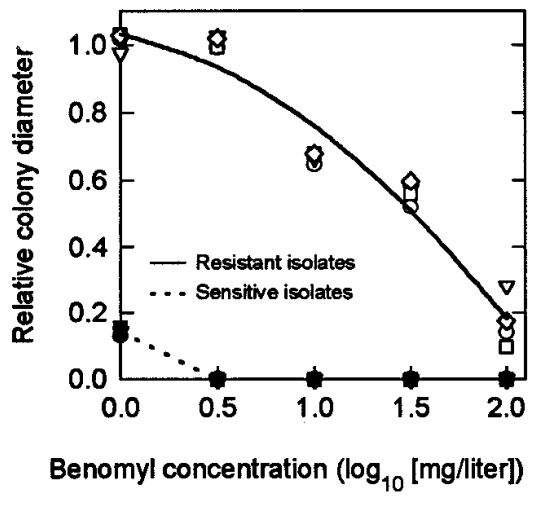

Fig. 1. Dose-response curves for four benomylresistant isolates of Didymella bryoniae (open symbols, solid line) and three benomyl-sensitive isolates (solid symbols, dashed line). Relative colony diameter $=($ diameter on benomylamended medium)/(diameter on nonamended medium). The $50 \%$ effective concentration value for insensitive isolates was 1.52 (33.1 $\mathrm{mg} /$ liter). Data were pooled from two experiments. plants treated with sterile distilled water). Data were analyzed with PROC GLM, SAS (version 6.10, SAS Inc., Cary, NC). Linear regression was used to compare dose-response curves of sensitive and resistant isolates. Relative disease severities of the two isolates at each benomyl concentration were compared with $t$ tests.

\section{RESULTS}

Fungicide resistance tests. Of the 7 isolates used in the first test, 3 isolates (C06, W03, and W6B) were sensitive (i.e., did not grow at $>1 \mathrm{mg}$ benomyl per liter), whereas 4 isolates (SSQ1, W04, W26, and NY1) were resistant (i.e., grew at all five concentrations of benomyl between 1 and 100 mg/liter; Fig. 1). Relative colony diameters did not differ within sensitivity classes ( $F$ test not significant, $P>0.50$ ). A quadratic equation best described the doseresponse curve for the resistant isolates: $y$ $=1.035-0.121 x-0.152 x^{2}\left(R^{2}=0.95\right)$, where $y=$ relative colony diameter and $x=$ $\log _{10}$ of benomyl concentration (mg/liter). The predicted $\mathrm{EC}_{50}$ value, the concentration of benomyl that reduced relative colony diameter of resistant isolates by $50 \%$, (i.e., relative colony diameter of $0.50 ; 20$ ), was $33.1 \mathrm{mg}$ benomyl per liter.

Of all 394 isolates tested at $33.1 \mathrm{mg}$ benomyl per liter, $53.8 \%$ (212) were sensitive and $46.2 \%$ (182) were resistant to benomyl (Table 1). Four isolates that had relative colony diameters $>0$ but $<0.10$ also were considered sensitive. Thirty-one isolates had relative colony diameters significantly greater than 0.5 on medium amended with $33.1 \mathrm{mg}$ benomyl per liter $(t$ tests, $P \leq 0.05)$. However, only those 17 isolates that had relative colony diameters $\geq 0.90$ on media amended with $50 \mathrm{mg}$ benomyl per liter, (i.e., also had relative colony diameters $\geq 0.95$ at $33.1 \mathrm{mg}$ benomyl per liter) were considered highly

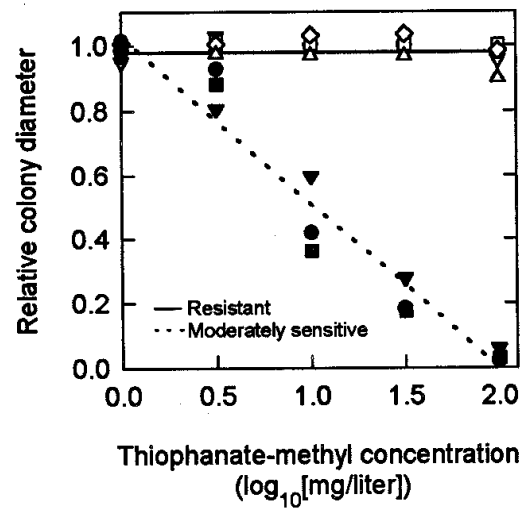

Fig. 2. Dose-response curves for five isolates of Didymella bryoniae resistant to thiophanatemethyl (open symbols, solid line) and three isolates moderately sensitive to thiophanatemethyl (solid symbols, dashed line). Relative colony diameter $=$ (diameter on fungicideamended medium)/(diameter on nonamended medium). Data were pooled from two experiments. resistant to benomyl. Relative colony diameters of highly resistant isolates B19, D17, J21, and K12 did not change between 1 and $100 \mathrm{mg}$ benomyl per liter, but were significantly greater than the relative colony diameter of resistant isolate NY1 at both 31.2 and $100 \mathrm{mg}$ benomyl per liter (Fisher's protected least significant difference, $P=0.05$ ). Highly resistant isolates accounted for $4.3 \%$ of all isolates and $9.3 \%$ of the resistant isolates. All of these isolates were collected from watermelon or cantaloupe fields in South Carolina in 1995.

All 137 isolates from the research plots and five commercial fields sampled in New York were sensitive to benomyl (Table 1). In contrast, only one of 24 field collections made in South Carolina was comprised entirely of sensitive isolates, but five of seven collections from seedlings grown in greenhouses consisted only of sensitive isolates. Within individual fields, the frequency of resistant isolates ranged from 0 to $100 \%$ for cantaloupe, 20 to $100 \%$ for watermelon, and 0 to $80 \%$ for pumpkin (Table 1). In the single fields of cucumber (South Carolina) and butternut squash (New York) sampled, 78\% and none of the isolates were resistant to benomyl, respectively. Of the 16 isolates representing 15 collections made in 1989 to 1992,1 isolate from New York (NY1), 3 isolates from Florida (FL1, W24, and W26), and 4 isolates from South Carolina (P3 and $\mathrm{P} 4$ [from the same collection], SSQ1, and W04) were resistant.

Response of $D$. bryoniae to thiophanatemethyl differed from the response of the fungus to benomyl. Of the first 8 isolates tested for resistance to thiophanate-methyl, 3 (C06, W03, and W6B) were moderately sensitive, (i.e., had reduced growth as the concentration of thiophanate-methyl increased), whereas 5 isolates (W04, W26, NY1, F18, and K12) were resistant, (i.e., growth was not reduced as the concentration of thiophanate-methyl increased; Fig. 2 ). There were no differences in relative colony diameter among moderately sensitive isolates $(F$ test not significant, $P=$ $0.58)$. The slight differences observed among resistant isolates, a range of 0.90 to 1.03 in relative colony diameter, were not significant. A linear equation best described the dose-response curve for the moderately sensitive isolates: $y=1.030-$ $0.551 x\left(R^{2}=0.93\right)$, where $y=$ relative colony diameter and $x=\log _{10}$ of thiophanatemethyl concentration ( $\mathrm{mg} /$ liter). The slope of the line for the resistant isolates was 0.99. Because an $\mathrm{EC}_{50}$ could not be calculated for resistant isolates, $100 \mathrm{mg} / \mathrm{liter}$ was selected as the concentration that would produce the maximum differences in relative colony diameters between sensitive and resistant isolates.

Relative colony diameters of $196 \mathrm{D}$. bryoniae isolates grown on media amended with $100 \mathrm{mg} / \mathrm{liter}$ thiophanate-methyl fell 
into three distinct classes (Fig. 3). Isolates that did not grow at all or grew very slightly, (i.e., had relative colony diameters of $\leq 0.02$ ), were classified as sensitive; isolates that had relative colony diameters of 0.03 to 0.10 were classified as moderately sensitive; and isolates that had relative colony diameters of 0.25 to 1.10 were classified as resistant. Most of the moderately sensitive isolates had relative colony diameters of 0.05 , whereas most of the resistant isolates had relative colony diameters of 0.95 or 1.00 (Fig. 3). Of 196 isolates tested at $100 \mathrm{mg}$ thiophanatemethyl per liter, $20.4 \%$ (40) were sensitive, $28.1 \%$ (55) were moderately sensitive, and $51.5 \%$ (101) were resistant. Of 78 isolates collected in South Carolina in 1995, 14 were sensitive, 6 were moderately sensitive, and 58 were resistant (Table 1). Of 40 isolates collected in four New York cantaloupe fields in 1996, 13 were sensitive, 27 were moderately sensitive, and none were resistant. The highest frequencies of moderately sensitive isolates were found in three of the four fields in New York, at 70, 100 , and $80 \%$, respectively (Table 1 ). Sensitive, moderately sensitive, and resistant isolates were found in two, three, and two South Carolina greenhouses, respectively (Table 1). In six of these seven greenhouses, all of the isolates from a given greenhouse fell into the same sensitivity class.

Ninety-five of 96 isolates $(99.0 \%)$ resistant to benomyl also were resistant to exception was a benomyl-resistant isolate collected from cantaloupe seedlings in thiophanate-methyl (Table 1). The one

South Carolina in 1993 that was classed as moderately sensitive to thiophanatemethyl. Five isolates that were sensitive to benomyl were resistant to thiophanatemethyl, although for 2 of these isolates relative colony diameters on thiophanatemethyl-amended medium were only 0.25 and 0.35 (Fig. 3). Thirty additional isolates, mostly from New York cantaloupe fields, were sensitive to benomyl and moderately sensitive to thiophanate-methyl (Table 1).

Disease severity comparisons. $D$. bryoniae NY1 resistant to benomyl incited gummy stem blight lesions both on watermelon plants not treated with benomyl and plants treated with benomyl concentrations of 1.5 to $1,500 \mathrm{mg} /$ liter (Fig. 4). Sensitive isolate W03 also caused disease on nontreated watermelon plants as well as on plants treated with 1.5 and $15 \mathrm{mg}$ benomyl per liter, but symptoms were greatly reduced on plants treated with 150 or 1,500 $\mathrm{mg} / \mathrm{liter}$. Across all three experiments, mean percent leaf area diseased on plants not treated with benomyl was $48.7 \pm 6.7 \%$ (standard error) for the sensitive isolate, which was greater than that for the resistant isolate, $27.3 \pm 8.3 \%$ ( $F$ test significant at $P=0.01$ ). Relative disease severity of the sensitive isolate decreased linearly as the concentration of benomyl was increased: $y=0.71-0.23 x\left(R^{2}=0.81\right)$, where $y=$ mean relative disease severity and $x=\log _{10}$ of benomyl concentration (mg/liter). Relative disease severity of the resistant isolate decreased quadratically as the concentration of benomyl was increased: $y=1.25+0.19 x-0.16 x^{2}\left(R^{2}=\right.$

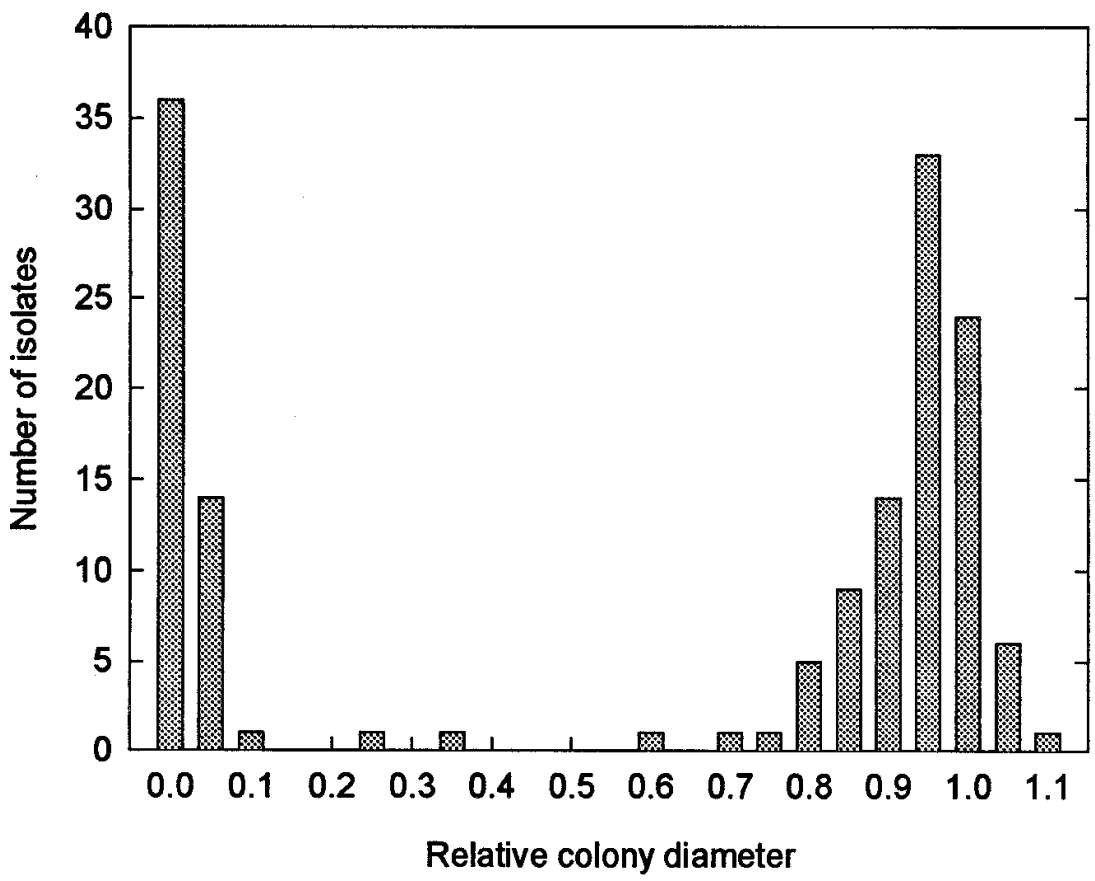

Fig. 3. Frequency distribution of 148 isolates of Didymella bryoniae based on colony diameter on medium amended with $100 \mathrm{mg}$ thiophanate-methyl per liter, relative to colony diameter on nonamended medium. Isolates were grouped as sensitive (relative colony diameter of 0 ), moderately sensitive (relative colony diameter of 0.05 to 0.10 ), and resistant (relative colony diameter $>0.20$ ).
0.68). Relative disease severity of the resistant isolate was significantly $(P \leq 0.02)$ greater than that of the sensitive isolate at all four benomyl concentrations. Disease caused by the resistant isolate on plants treated with $1,500 \mathrm{mg}$ benomyl per liter was still $25 \%$ of that on nontreated plants (Fig. 4).

\section{DISCUSSION}

Relative colony diameters of $D$. bryoniae on fungicide-amended media fell into four classes: no growth at $>1 \mathrm{mg} / \mathrm{liter}$ fungicide, radial growth decreasing at a constant rate (i.e., linearly), radial growth decreasing at an increasing rate (quadratically), or little to no decrease in growth as the fungicide concentration was increased. On benomyl-amended media, most isolates either did not grow or had relative colony diameters that decreased quadratically to a predicted value of 0.19 at $100 \mathrm{mg} / \mathrm{liter}$. These two responses were classified as sensitive and resistant to benomyl, respectively. Less than $5 \%$ of the isolates tested showed no decrease in radial growth at $100 \mathrm{mg}$ benomyl per liter. With thiophanate-methyl, however, isolates either did not grow, had relative colony diameters that decreased linearly to a predicted value of 0 at $100 \mathrm{mg} / \mathrm{liter}$, or showed no decrease in radial growth up to $100 \mathrm{mg} / \mathrm{liter}$. These three responses were classified as sensitive, moderately sensitive, and resistant to thiophanate-methyl, respectively. The three sensitivity classes observed with thiophanate-methyl were similar to the range of sensitivity to thiabendazole reported for Fusarium sambucinum (6). For both benomyl and thiophanate-methyl, all sensitive and moderately sensitive isolates of $D$. bryoniae had relative colony diameters $\leq 0.10$ at the discriminatory dose of fungicide $(33.1 \mathrm{mg}$ benomyl or $100 \mathrm{mg}$ thiophanate-methyl per liter).

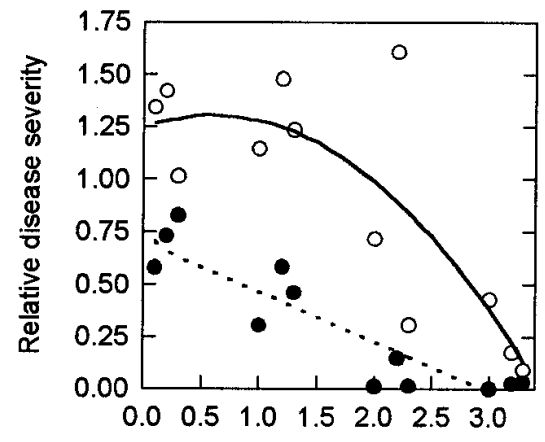

Benomyl concentration $\left(\log _{10}[\mathrm{mg} /\right.$ liter $]$ )

Fig. 4. Effects of four concentrations of benomyl on severity of gummy stem blight on watermelon plants treated with benomyl 1 day before inoculation with an isolate of Didymella bryoniae resistant (open circles, solid curve) or sensitive (solid circles, dashed line) to benomyl. Each data point is the mean rating on 12 plants. 
Benomyl- and thiophanate-methyl-resistant isolates of $D$. bryoniae were recovered frequently from commercial cucurbit crops in South Carolina. No benomyl- or thiophanate-methyl-resistant isolates of this pathogen were recovered in New York, except one isolate (NY1) collected in 1990. All of the isolates obtained in commercial cantaloupe fields in New York in 1996 were sensitive to benomyl and sensitive or moderately sensitive to thiophanate-methyl. Additionally, only benomyl-sensitive isolates were recovered from butternut squash and pumpkin sampled in New York in 1994 and 1995, respectively, even though both of these crops had been treated with benomyl before sampling. The research plots of butternut squash received five applications of benomyl or benomyl combined with chlorothalonil (31), and the commercial pumpkin field received one application of benomyl alone followed by two applications of benomyl plus chlorothalonil. In contrast, a majority $(80 \%)$ of the isolates collected in commercial fields in South Carolina between 1992 and 1995 were resistant to benomyl and thiophanate-methyl. The oldest $D$. bryoniae isolate that was resistant to benomyl was recovered in 1989 from cantaloupe breeding plots in Florida. The first benomyl-resistant isolates recovered from commercial crops were found in Onondaga County in New York in 1990 and Charleston and Colleton counties in South Carolina in 1991.

The high frequency of benomyl-resistant isolates in South Carolina may be due to widespread use of benomyl. For example, the three cantaloupe fields sampled in Colleton County in 1993 to 1995 and the watermelon field on Edisto Island sampled in 1995 received approximately eight weekly applications of $0.28 \mathrm{~kg} / \mathrm{ha}$ benomyl mixed with $1.7 \mathrm{~kg} / \mathrm{ha}$ mancozeb. Such heavy use of benomyl runs contrary to recommendations which limit the number of applications of fungicides with the potential for inducing resistance (4). Although the dithiocarbamate fungicide mancozeb was combined with benomyl in the example cited, the rates were disproportionate to those advocated by Delp (3), who suggested the minimum labeled rate of a benzimidazole $(0.14 \mathrm{~kg} / \mathrm{ha}$ in this case) be applied together with the maximum labeled rate of the companion fungicide $(2.5 \mathrm{~kg} / \mathrm{ha})$. The frequent occurrence of resistant isolates in South Carolina also may be due to aerial dispersal of resistant isolates, as has been reported previously for $D$. bryoniae in the southeastern United States (24). Migration of resistant isolates could explain why 1 and 9 of 20 D. bryoniae isolates were highly resistant and resistant to benomyl, respectively, in a cantaloupe field in Chesterfield County, South Carolina, in 1995, although the crop had not been treated with benomyl before sampling. There was no indication that the resistant isolates originated from seed or inoculum overwintering in the soil in this field.

Staub (26) has suggested that fungicide-resistant isolates appear first on susceptible hosts in areas with high disease pressure. The two cucurbit crops most frequently grown in South Carolina, watermelon and cantaloupe, generally have more foliage affected with gummy stem blight than winter squash or pumpkin, cucurbits more commonly grown in New York (12,31). The southeastern United States also has higher annual rainfall than the northeastern region, which provides environmental conditions suited for rapid reproduction of $D$. bryoniae $(24,28)$. Thus, the potentially greater pathogen populations exposed to benomyl within a given field in South Carolina may partially explain the development of benomyl resistance in South Carolina rather than in New York.

In general, isolates recovered from greenhouse-grown transplants in South Carolina were sensitive to benomyl, except for two collections in 1994 and 1996. Isolates from greenhouses would be expected to be sensitive, since benomyl is no longer registered for use in greenhouses. None of the seedlings from which sensitive isolates were collected had been treated with benomyl. It could not be determined if benomyl had been applied to the cantaloupe seedlings from which resistant isolates were recovered. D. bryoniae isolates resistant to benomyl were found in greenhouses on Crete within 1 year of the first use of benomyl (18). Likewise, benomyl resistance in Verticillium fungicola was correlated with the introduction of this fungicide in mushroom production facilities (1).

Seventeen isolates of $D$. bryoniae collected in South Carolina in 1995 were highly resistant to benomyl; no highly resistant isolates were found in earlier collections or in New York. Seven of the eight watermelon and cantaloupe fields in which these isolates were collected had been treated with benomyl before sampling in 1995. The higher level of resistance to benomyl may be due to the presence of a different allele for benomyl resistance than that in the majority of the resistant isolates. Benomyl resistance in Venturia inaequalis is controlled by four different alleles, which confer different levels of resistance to the fungicide $(10,16)$.

The occurrence of benomyl-resistant isolates that are as fit as sensitive isolates has been observed with most genera of fungi in which benzimidazole resistance has been documented $(4,26)$. Benzimidazole-resistant $D$. bryoniae NY1 incited gummy stem blight on benomyltreated and nontreated watermelon plants. Although disease severity was lower with the resistant isolate than with the sensitive isolate used in these tests, disease severity was within the range (1 to $42 \%$ ) for 19 isolates of $D$. bryoniae that were tested previously (13). In Greece, gummy stem blight progressed more slowly with a benomyl-resistant isolate during the first 2 days after inoculation, but no differences were found between a sensitive and a resistant isolate after 4 days (18).

The $\mathrm{EC}_{50}$ value used in this study to test isolates for resistance to benomyl was determined from the response of a representative group of isolates, as was done previously in a study on thiabendazole resistance (20). The $\mathrm{EC}_{50}$ of $33.1 \mathrm{mg}$ benomyl per liter was near the median of the values used in other recent studies on benomyl resistance with different fungal pathogens, 3 (21), 5 (8), 30 (30), 50 (1), and 200 (19) $\mathrm{mg} / \mathrm{liter}$. In the Netherlands, benomyl resistance in $D$. bryoniae was determined at $5 \mathrm{mg} / \mathrm{liter}$ (29). In Greece, the $\mathrm{EC}_{50}$ for sensitive isolates was found to be $1.2 \mathrm{mg}$ of benomyl per liter (18). However, the $\mathrm{EC}_{50}$ of $716 \mathrm{mg} / \mathrm{liter}$ reported for resistant isolates is likely invalid, because use of an organic solvent was not reported and benomyl is insoluble in water.

Thiophanate-methyl was less inhibitory to $D$. bryoniae than was benomyl. For example, at $100 \mathrm{mg}$ thiophanate-methyl per liter, relative growth of resistant isolates was not reduced, but at $100 \mathrm{mg}$ benomyl per liter, relative growth of most resistant isolates was $<20 \%$. In Greece, benomylresistant $D$. bryoniae was able to incite gummy stem blight on cucumbers treated with $300 \mathrm{mg} / \mathrm{liter}$ thiophanate-methyl (18). Five isolates from South Carolina were sensitive to benomyl but were resistant to thiophanate-methyl. It is possible that the allele that confers resistance to thiophanate-methyl is not the same allele that confers resistance to benomyl.

Because of the widespread resistance of D. bryoniae to the only two systemic fungicides registered in 1997 for control of gummy stem blight and black rot, growers in South Carolina will have to rely more heavily on the protectant fungicides mancozeb, maneb, and chlorothalonil. This increased reliance may necessitate more frequent applications of fungicides, higher rates, or initiating applications earlier and extending them later in the growing season. Because a single benomyl-resistant isolate was recovered from one location in New York, the potential exists for development of benomyl resistance in D. bryoniae in other areas of the state. Growers may be able to delay development of resistance by judiciously applying benomyl in combination with protectant fungicides and only using benomyl early in the growing season $(3,19,26)$.

\section{ACKNOWLEDGMENTS}

We thank W. May III, J. Drennan, Y. Allston, A Rowell, T. Zuniga, P. Jiminez, and B. Somai for technical assistance; and R. Loria and S. N. Jeffers for reviewing this manuscript. 


\section{LITERATURE CITED}

1. Bonnen, A. M. 1994. Fungicide resistance in Verticillium fungicola, a mycopathogen of Agaricus bisporus. (Abstr.) Phytopathology $84: 1138$.

2. Davidse, L. C. 1986. Benzimidazole fungicides: Mechanism of action and biological impact. Annu. Rev. Phytopathol. 24:43-65.

3. Delp, C. J. 1988. Resistance management strategies for benzimidazoles. Pages 41-43 in: Fungicide Resistance in North America, C. J. Delp, ed. American Phytopathological Society, St. Paul, MN.

4. De Waard, M. A., Georgopoulos, S. G., Hollomon, D. W., Ishii, H., Leroux, P., Ragsdale, N. N., and Schwinn, F. J. 1993. Chemical control of plant diseases: problems and prospects. Annu. Rev. Phytopathol. 31:403-421.

5. Duthie, J., Roberts, W., and Thannisch, T. 1995. Weather-based schedules for fungicidal control of watermelon anthracnose. (Abstr.) Phytopathology 85:510.

6. Hanson, L. E., Schwager, S. J., and Loria, R. 1996. Response of Fusarium isolates from potato tubers to benzimidazole fungicides. Phytopathology 86:378-384.

7. Horsfall, J. G., and Barratt, R. W. 1945. An improved system for measuring plant diseases. (Abstr.). Phytopathology 35:655.

8. Johnson, K. B., Sawyer, T. L., and Powelson, M. L. 1994. Frequency of benzimidazole- and dicarboximide-resistant strains of Botrytis cinerea in western Oregon small fruit and snap bean plantings. Plant Dis. 78:572-577.

9. Kantzes, J. G. 1980. Gummy stem blight control with fungicides, 1978. Fungic. Nematic. Tests 35:68.

10. Katan, T., Shabi, E., and Gilpatrick, J. D. 1983. Genetics of resistance to benomyl in Venturia inaequalis isolates from Israel and New York. Phytopathology 73:600-603.

11. Kato, T., Suzuki, K., Takahashi, J., and Kamoshita, K. 1984. Negatively correlated cross-resistance between benzimidazole fun- gicides and methyl $N$-(3,5-dichlorophenyl)carbamate. J. Pestic. Sci. 9:489-495

12. Keinath, A. P. 1995. Fungicide timing for optimum management of gummy stem blight epidemics on watermelon. Plant Dis. 79:354358.

13. Keinath, A. P., Farnham, M. W., and Zitter, T. A. 1995. Morphological, pathological, and genetic differentiation of Didymella bryoniae and Phoma spp. isolated from cucurbits. Phytopathology 85:364-369.

14. Keinath, A. P., and Zitter, T. A. 1995. First report of benomyl-insensitive Didymella bryoniae in the United States. (Abstr.) Phytopathology 85:1126.

15. Keinath, A. P., Zitter, T. A., and Somai, B. M. 1996. Cross-resistance to thiophanate-methyl in Didymella bryoniae resistant to benomyl. (Abstr.) Phytopathology 86:S31.

16. Koenraadt, H., Somerville, S. C., and Jones, A. L. 1992. Characterization of mutations in the beta-tubulin gene of benomyl-resistant field strains of Venturia inaequalis and other plant pathogenic fungi. Phytopathology 82:1348-1354.

17. Latin, R. X. 1992. Evaluation of fungicides for control of anthracnose on watermelon, 1991. Fungic. Nematic. Tests 47:157.

18. Malathrakis, N. E., and Vakalounakis, D. J. 1983. Resistance to benzimidazole fungicides in the gummy stem blight pathogen Didymella bryoniae on cucurbits. Plant Pathol. 32:395-399.

19. McGrath, M. T., Staniszewska, H., Shishkoff, N., and Casella, G. 1996. Fungicide sensitivity of Sphaerotheca fuliginea populations in the United States. Plant Dis. 80:697-703.

20. Mérida, C. L., and Loria, R. 1994. Comparison of thiabendazole-sensitive and -resistant Helminthosporium solani isolates from New York. Plant Dis. 78:187-192.

21. Murray, T. D. 1996. Resistance to benzimidazole fungicides in the cereal eyespot pathogen, Pseudocercosporella herpotrichoides, in the Pacific Northwest 1984 to 1990. Plant
Dis. 80:19-23.

22. Ogawa, J. M., Gilpatrick, J. D., and Chiarappa, L. 1977. Review of plant pathogens resistant to fungicides and bactericides. FAO Plant Prot. Bull. 25:97-111.

23. Pearson, R. C., and Taschenberg, E. F. 1980 Benomyl-resistant strains of Uncinula necator on grapes. Plant Dis. 64:677-680.

24. Schenck, N. C. 1968. Epidemiology of gummy stem blight (Mycosphaerella citrullina) on watermelon: ascospore incidence and disease development. Phytopathology 58:1420-1422.

25. Smith, D. H., and Crosby, F. L. 1972. Effects of foliar applications of a benomyl-oil-water emulsion on the epidemiology of Cercospora leaf spot on peanuts. Phytopathology 62:1029-1031.

26. Staub, T. 1991. Fungicide resistance: Practical experience with antiresistance strategies and the role of integrated use. Annu. Rev. Phytopathol. 29:421-442.

27. Svedelius, G., and Unestam, T. 1978. Experimental factors favoring infection of attached cucumber leaves by Didymella bryoniae. Trans. Brit. Mycol. Soc. 71:89-97.

28. Van Steekelenburg, N. A. M. 1978. Chemical control of Didymella bryoniae in cucumbers. Neth. J. Plant Pathol. 84:27-34.

29. Van Steekelenburg, N. A. M. 1987. Resistance to benzimidazole and dicarboximide fungicides in Botrytis cinerea and Didymella bryoniae in cucumbers in the Netherlands. Med. Fac. Landbouww. Rijksuniv. Gent. 52:875880.

30. Ypema, H. L., Ypema, M., and Gubler, W. D. 1997. Sensitivity of Uncinula necator to benomyl, triadimefon, myclobutanil, and fenarimol in California. Plant Dis. 81:293297.

31. Zitter, T. A., Drennan, J. L., and Derksen, R. C. 1995. Comparison of hydraulic and electrostatic sprayers for fungicide applications in winter squash, 1994. Fungic. Nematic. Tests 50:162. 